\title{
DIGITAALISEN PELAAMISEN HISTORIANTUTKIMUS SUOMESSA
}

\begin{abstract}
Käsittelen artikkelissani digitaalisen pelaamisen historiantutkimusta Suomessa. Jaan tutkimuksen ennen vuotta 2009 tapahtuneeseen varhaisvaiheeseen, jolloin aihepiiriä koskevat tutkimukset julkaistiin pitkälti suomeksi ja suomalaiselle yleisölle ja jolloin tutkimukset olivat muutamaa poikkeusta lukuun ottamatta yleisesityksiä ja sitoivat pelaamisen erityisesti tietokoneharrastamiseen. Vuoden 2009 jälkeen digitaalista pelaamista käsittelevä tutkimus on lisääntynyt ja laajentunut suomenkielisenä Pelitutkimuksen vuosikirjan tapaisten julkaisukanavien kautta, ja suomalaiset tutkijat osallistuvat entistä useammin myös kansainväliseen tutkimuskeskusteluun, jossa on viime vuosina painotettu monesti kansallisten ja paikallisten erityispiirteiden ja vertailevan tutkimuksen tarvetta.
\end{abstract}

\section{Johdanto}

Digitaalinen pelaaminen alkoi yleistyä Suomessa, kuten monessa muussakin maassa, 1980-luvun alkupuolella. Jo sitä ennen pelejä oli ollut olemassa, mutta niiden pelaaminen oli ollut marginaalisempaa. 1980-luvun alussa digitaalisia pelejä pelattiin muun muassa kolikoilla toimineilla videopeleillä julkisissa tiloissa, varhaisilla kotikonsoleilla sekä kannettavilla elektroniikkapelilaitteilla, mutta varsinainen pelaamisen nousu liittyi kotitietokoneiden yleistymiseen.

Samalla, kun digitaalinen pelaaminen laajentui ja yleistyi, myös sitä koskeva historiankirjoitus alkoi kehkeytyä. Aluksi pelihistoriaa kirjoittivat alan harrastajat sekä tietokonealan harrastuslehtien, kuten MikroBitin, Printin ja C-lehden toimittajat ja avustajat. Myös Raha-automaattiyhdistyksen asiakas- ja henkilöstölehdissä (Potti, Pajazzo) julkaistiin joitakin pelihistoriaan liittyneitä katsauksia.

Ammatti- ja harrastuslehdissä ilmestyneet kirjoitukset käsittelivät pitkälti digitaalisen pelaamisen yhdysvaltalaisia ja japanilaisia juuria ja menestystarinoita mainiten Pongin (1972), Space Invadersin (1978) ja Pac-Manin (1980) kaltaisia kaupallisia menestystarinoita. Jutuissa oli myös jonkin verran kotimaisia esimerkkejä, jotka liittyivät muun muassa Raha-automaattiyhdistyksen videopelitoimintaan sekä tietokonepelaamiseen Suomessa.

Journalistinen pelihistoriointi alkoi monimuotoistua 1980-luvun lopulta lähtien, kun kirjoittajilla - samoin kuin kohdeyleisöllä - alkoi olla yhä laajempaa tietämystä peleistä ja pelikulttuureista. Ja varsinkin 2000-luvulla journalisti- ja harrastajalähtöinen historiankirjoitus on alkanut perustua aikaisempaa vankempaan lähteiden käyttöön, ei pelkästään esimerkiksi ulkomailla ilmestyneiden juttujen referointiin. Lähteinä on käytetty esimerkiksi haastatteluita ja alkuperäisaineistoja, kuten itse pelejä ja pelimainoksia. Tällaisesta tarkastelutavasta parhaita esimerkkejä ovat toi- 
mittaja Juho Kuorikosken suomalaista ja muuta pelihistoriaa ja tietokonekulttuuria käsittelevät tietokirjat, kuten Sinivalkoinen pelikirja - Suomen pelialan kronikka (2014) sekä Commodore 64 - Tasavallan tietokone (2017).

Populaarikirjoittajilla ja muita historiaesityksiä tuottavilla on ollut kaksi tyypillistä perusprofiilia: perehtynyt toimittaja ja perehtynyt pelikeräilijä. Nämä profiilit ovat saattaneet sekoittua, mutta ne ovat myös osittain johtaneet erilaisiin painotuksiin esimerkiksi siinä, missä asemassa pelintekijät ja pelaajat ovat historiaesityksissä ja missä määrin pyritään käymään läpi pelejä historiallisen tuotekatalogin tavoin mahdollisimman kattavasti (ks. lisää Suominen 2016).

Tässä katsauksessa en tarkastele tämän enempää populaaria pelihistoriankirjoitusta. Käsittelen sen sijaan sitä, miten digitaalisia pelejä ja pelikulttuureja käsittelevä akateeminen historiantutkimus on kehkeytynyt Suomessa. Miten se on tullut esille ensin erityisesti suomenkielisinä ja sittemmin myös esimerkiksi englanninkielisinä julkaisuina. Pohdin syitä kansallisen tutkimuksen erityispiirteille ja esittelen tarkemmin yksitäisiä suomalaisia tutkimusesimerkkejä.

\section{Käänne kriittiseen ja paikalliseen}

Digitaalista pelaamista koskeva ammattimainen ja akateeminen historiantutkimus on huomattavasti harrastaja- ja amatöörihistoriointia uudempi ilmiö. Akateeminen digitaalisten pelien historiantutkimus on lisääntynyt 2010-luvulla, jolloin on alettu aiempaa vahvemmin painottaa muun muassa pelaamisen kansallisia ja paikallisia erityispiirteitä. Uudet tutkimukset ovat eksplikoineet sen, että pelit ja pelaaminen eivät ole samanlaista kaikkialla, vaikka tietenkin maiden ja alueiden pelikulttuureissa on yhtymäkohtia ja pelituotteet ovat levinneet valtiorajojen yli osana kansainvälistä teknologia- ja mediateollisuutta ja muuta vuorovaikutusta. Tutkimusalan pioneerin Melanie Swalwellin (2015) mukaan paikallisten pelihistorioiden ei ole tarkoitus korvata aiempaa tutkimuksellista lähestymistapaa uudella vaan tarkastella kriittisesti paikan ja paikallisuuden kysymyksiä (ks. myös esim. Swalwell 2005; Stuckey ym. 2015).

Uudessa, monesti englanniksi julkaistavassa tutkimuksessa tarkastellaan monipuolisesti myös peleihin liittyvien kulttuuriperintöyhteisöjen roolia historiatuotannossa ja pohditaan pelien ja pelikulttuurien tallentamiseen, säilyttämiseen ja esittelemiseen liittyviä kysymyksiä. ${ }^{1}$ Hyvä esimerkki tuoreesta pelihistorian tutkimuksesta on Jaroslav Švelchin teos Gaming the Iron Curtain (2018). Teoksessaan Švelch tarkastelee tšekkoslovakian digipelikulttuureita ja tietokoneharrastuskulttuureja erityisesti 1980-luvulla vertaamalla niitä etenkin muihin Itä-Euroopan maihin mutta myös Pohjoismaihin, Länsi-Eurooppaan sekä Yhdysvaltoihin.

Mutta jo ennen 2010-lukua monissa digitaalisen pelihistorian tutkimuksissa on painotettu kansallisia ja paikallisia erityispiirteitä. Aiempi tutkimus, jota on tehty jo 1990-luvulta lähtien, ei kuitenkaan ole ollut niin näkyvää, koska sitä on julkaistu englannin sijasta monesti kansallisilla kielillä. Varhaisemmissa tutkimuksissa ei myöskään ole artikuloitu kansallisen tai paikallisen näkökulman tärkeyttä yhtä vahvasti kuin nykyään, vaikka ne ovat perustuneet nimenomaan kansallisten ja paikallisten tapausten käsittelyyn ja monissa tapauksissa ovat olleet tietoisia myös kansainvälisistä tutkimuksellisista keskusteluista. Niissä kansallisen tai paikallisen näkökulman tärkeys on nähty niin itsestään selvänä, ettei sitä ole tarvinnut alleviivata.

\footnotetext{
${ }^{1}$ Erilaisista pelihistorian kirjoittamisen tavoista ks. Suominen 2016.
} 
Yhä nykyäänkin digitaalisia pelejä ja pelikulttuureja koskevaa historiantutkimusta julkaistaan muilla kielillä kuin englanniksi. Kansallisilla kielillä julkaiseminen on luultavasti yleisempää suurilla kielialueilla, mutta sitä tapahtuu myös pienemmissä maissa, kuten Suomessa. Kansallisilla kielillä julkaistu historiankirjoitus näkyy kuitenkin kansainvälisessä tutkimuskentässä ainoastaan siltä osin, kun englanniksi kirjoittavat hallitsevat muita kieliä ja viittaavat mahdollisesti ei-englanninkieliseen tutkimukseen.

\section{Miksi julkaista kansallisilla kielillä}

Syitä varhaisemmalle - ja nykyisellekin - ei-englanninkieliselle julkaisemiselle on useita. Erityisesti humanististen tieteiden piirissä omakielinen julkaiseminen on ollut tavallista myös pienillä kielialueilla, joilla tutkijat ovat aktiivisesti osallistuneet kansalliseen keskusteluun ja halunneet kehittää omakielistä tieteellistä terminologiaa. Kieli on siis työväline, jonka avulla ilmiötä tutkitaan ja käsitteellistetään. Kansalliseen julkaisemiseen on siten liittynyt oma henkilökohtainen tai poliittinen arvolatauksensa, jossa kyse ei ole ollut yleensä nationalistisesta ajattelutavasta vaan pikemminkin halusta oman kulttuuri- ja kieliperinnön säilyttämiseen. Suuremmilla ei-englanninkielisillä kielialueilla, kuten espanjan-, saksan- ja ranskankielisissä maissa sekä Japanissa, on myös ollut itsessään niin vakiintuneet julkaisufoorumit ja yleisöt, ettei englanninkielinen julkaiseminen ole ollut tarpeen.

Vielä vuosituhannen vaihteessa monilla humanistisilla tieteenaloilla, kuten historiassa, kirjallisuustieteessä ja etnologiatieteissä, omakielinen julkaiseminen oli Suomessakin tavanomaisempaa kuin englanniksi julkaiseminen. Täytyy toki muistaa, että samoilla tieteenaloilla oli saatettu aiemmin julkaista enemmän vaikkapa saksaksi tai ranskaksi. Näiden tieteenalojen julkaisukäytänteet periytyvät kansallisten tieteiden nousuun 1800-luvulla ja yleisempään kielipolitiikkaan sidoksissa olleeseen ajatukseen omakielisen tieteellisen tutkimuksen tuottamisesta. Tämä kehitystausta on saattanut hämärtyä, mutta vielä 1990-luvulla ja myöhemminkin omakielinen julkaiseminen on ollut kotimaisten aiheiden osalta niin itsestään selvää, ettei sitä monikaan todennäköisesti ole ajatellut minään erityisenä arvovalintana tai julkilausumana.

Tietoisen tutkimuspoliittisen agendan lisäksi kyse on ollut osaamisesta. Kielitaito on vaikuttanut julkaisemiseen. Jos kirjoittaminen on onnistunut omalla kielellä, tutkija ei ole välttämättä kehittänyt vieraskieliseen kirjoittamiseen riittävää kielitaitoa, vaikka on lukenut muun kielistä tutkimuskirjallisuutta ja aineistoa. Myöskään tutkimuksen kääntäminen tai edes kielentarkastus ei välttämättä ole onnistunut kustannussyistä. Kun kotimainen tiedeyhteisö piti kansallista julkaisemista itsestään selvänä, niin kääntämiseen ja kielentarkastukseen ei välttämättä tarjottu institutionaalista tukea 1990-luvulla ja 2000-luvun alussa. Jos kansallisia tieteitä edustanut tutkija halusi julkaista tutkimuksiaan vieraalla kielellä, hän saattoi joutua vastaamaan kielentarkastus- ja käännöskuluistaan itse. Tällaisesta minullakin on omakohtaisia kokemuksia.

Keskeinen syy omalla kielellä julkaisemiseen on saattanut myös liittyä käsitykseen yleisöistä. Koska omakielinen tutkimus on tyypillisesti liittynyt oman maan ilmiöihin, tutkija on voinut ajatella, ettei tutkimus kiinnosta oman maan ulkopuolella. Ulkomaiselle lukijalle tutkimuksen suomalainen kohde on motivoitava ja kontekstualisoitava eri tavoin kuin suomalaiselle lukijalle. Tutkija on saattanut kokea myös, että erityisen paikallisen ja spesifin tapauksen ja käsittelytavan kääntäminen vieraalle kielelle olisi vaikeaa. Jos tutkija käsittelee vaikkapa varhaisten suomenkielisten tietokoneiden nimeämiskäytänteitä osana tietokoneiden popularisaatiota, suomalaiselle lukijakunnalle voi riittää toteamus, että varhainen matematiikkakone 
ESKO oli ajan tavan mukainen lyhennelmä, tässä tapauksessa sanoista Elektroninen Sarja-KOmputaattori, mutta myös tietynlainen viittaus Aleksis Kiven Nummisuutareiden Eskoon. Kansainväliselle lukijakunnalle Aleksis Kiveä ja Nummisuutareita pitää selittää laajemmin ja eri tavalla. (Paju 2008; Suominen \& Parikka 2010.)

Seuraavaksi esittelen suomenkielistä pelien ja pelikulttuurin historiaan liittyvää tutkimusta. Todennäköisesti en ole löytänyt kaikkea olemassa olevaa tutkimusta, ja pelihistorian tutkijoita ja tutkimuksia löytyy lukuisia muitakin kuin tässä käsiteltävät. Keskityn erityisesti digitaalisiin peleihin ja lautapeleihin liittyvään tutkimukseen. En siis käsittele kaikkea suomeksi julkaistua pelitutkimusta enkä myöskään simulaatioiden tai oppimispelien historiaan liittyvää tutkimusta, koska ne ovat itselleni vieraampia ja ylipäätään vähemmän tutkittuja alueita.

\section{Digitaalisten pelien akateemisen historiantutkimuksen alku Suomessa}

Pelejä ja leikkejä on Suomessa tutkittu jo 1900-luvun alusta lähtien erityisesti perinteentutkimuksen piirissä (Sotamaa 2009). 1990-lopulla Suomessa alkoi kuitenkin nousta esiin pieni historiantutkijoiden joukko, jolla oli omaa tietokoneharrastamisen taustaa ja joka halusi käsitellä tietotekniikkaan liittyviä teemoja tutkimuksissaan. Pelihistoriaan liittynyt kiinnostus syntyi teknologian tai tietotekniikan historian sekä mediahistorian rajapinnalla, ja tästä löytyi esikuvia Suomen ulkopuolelta. Esimerkiksi brittiläisessä ja pohjoismaisessa median domestikaatiota ja arkipäiväistymistä koskevassa tutkimuksessa käsiteltiin radion ja etenkin television ja videonauhurien kotitalouskäytön lisäksi myös kotitietokoneiden yleistymistä ja pelaamista kotitietokoneiden käytön yhtenä osa-alueena.

1990-luvun puolivälissä Turun yliopiston kulttuurihistorian oppiaineessa perustettiin tutkimusryhmä, joka alkoi kehittää historia-alan verkkoportaalia ${ }^{2}$ mutta suuntautui samalla myös teknologian ja tietotekniikan historian tutkimukseen. Muun tutkimuksen ohessa jotkut ryhmän jäsenet julkaisivat myös digipelihistoriaan liittyneitä artikkeleita (esim. Saarikoski 1998; 1999a; 1999b; 1999c; Suominen 1999), mutta aluksi digipeliaiheita saatettiin pitää liian tuoreina lyhyen aikavälin ilmiöinä, eikä ajallisen etäisyyden tai keston puutteen takia aiheisiin välttämättä tartuttu historiantutkimuksen menetelmin.

Ensimmäiset artikkelit olivat yleensä yleisesityksiä, joita julkaistiin esimerkiksi elektronista, digitaalista tai uutta mediaa käsitelleissä kokoomateoksissa tai lehdissä. Historiaan liittyneitä artikkeleita ilmestyi myös varhaisissa digitaalisia pelejä käsitelleissä konferenssijulkaisuissa (esim. Honkela 1999). Myös nämä artikkelit olivat alustavia katsauksia siihen, mitä ylipäätään digitaalinen pelaaminen on ja millaisista suunnista historiantutkimus voisi sitä lähestyä muutenkin kuin analysoimalla historiapelien tuottamaa historiakuvaa. Jo tässä vaiheessa tutkijoista Petri Saarikoski (1999a; 1999d; 2001; 2003) alkoi käyttää lähteinään kotimikrolehtiä ja analysoida pelaamista osana kotimikrokulttuuria. Kansainvälisestikin pelihistorian tutkimuksessa lähteinä on käytetty usein harrastuslehtiä, koska muuta lähdeaineistoa ei ole välttämättä ollut helposti saatavilla. Lehdet myös muodostavat monesti pitkiä aikasarjoja ja kertovat harrastuskulttuureista monipuolisesti. (Ks. esim. Kirkpatrick 2012.) Nykyään lähdeaineistot ovat toki monimuotoistuneet.

Lehtiaineiston käyttö liittyi yleisempään tendenssiin tietotekniikan kulttuurihistorian tutkimusryhmässä Turun yliopistossa. Lehtiaineiston saaminen tutkimus-

\footnotetext{
2 Aluksi portaali oli nimeltään Suomen historian elektroninen keskus SHEK, myöhemmin Agricolaportaali (https://agricolaverkko.fi/).
} 
käyttöön oli varsin vaivatonta yliopistokirjastojen ja omien kokoelmien kautta, ja toisaalta lehtien merkitys suomalaisen kotimikro- ja pelikulttuurien määrittämisessä oli keskeinen. Tutkimus inspiroitui muun muassa Hannu Salmen (esim. 1996) teknologian ja median kulttuurihistoriaa käsittelevästä tutkimuksesta ja pian myös esimerkiksi teknologian domestikaatiotutkimuksesta (esim. Pantzar 1996). Pelihistorian ja -kulttuurien varhaisemmasta tutkimuksesta tutkijat hyödynsivät muun muassa brittiläisen Leslie Haddonin mikrotietokoneiden käyttöön liittyneitä tutkimuksia (esim. Haddon 1988; 1992; ks. myös Haddon 2002).

Kulttuurihistoriaan kytkeytyvät myös Turun yliopistossa kulttuurihistoriaa opiskelleen ja sinne väitelleen Erkki Huhtamon media-arkeologiset tutkimukset. Huhtamon tutkimukset liittyivät alkuvaiheissa erityisesti elävän kuvan arkeologiaan, mutta hän on käsitellyt monia muitakin teemoja, myös pelejä. Huhtamo onkin myös pelitutkimuksen puolella tunnettu kirjoittaja, joka on käsitellyt erityisesti automaattipelaamisen ei-digitaalisia juuria (Huhtamo 2002; Huhtamo 2005; Huhtamo 2012; media-arkeologisesta pelitutkimuksesta ks. myös Parikka \& Suominen 2006).

Jaakko Suominen julkaisi 2003 kulttuurihistorian väitöskirjansa Koneen kokemus, jossa hän tarkasteli erityisesti robottien ja tietokoneiden julkista ja populaaria käsittelyä 1920-luvulta 1970-luvulle, jolloin tietokoneita ei vielä ollut kotitalouksissa mutta jolloin monet kansalaiset kuitenkin törmäsivät tietotekniikkaan vähintään epäsuorasti tai kuviteltuna teknologiana. Suominen sivusi teoksessaan pelejä pariin otteeseen, samoin kuin muissa tutkimusteksteissään (Suominen 1999; 2001).

Laajin tietokoneharrastamista ja pelaamista käsitelleistä varhaisista suomenkielisistä - eli karkeasti määritellen ennen vuotta 2009 ja silloin aloittanutta Pelitutkimuksen vuosikirjaa aiemmin julkaistuista - tutkimuksista on ollut Petri Saarikosken yleisen historian väitöskirja Koneen lumo (2004). Saarikoski tarkasteli siinä ajanjaksoa 1970-luvulta 1990-luvulle lähteinään erityisesti suomalaiset mikrotietokoneharrastuslehdet ja pelilehdet. Saarikosken esittelemät näkökulmat ja teoreettis-metodologiset lähestymistavat ovat sellaisia, että vastaavantyyppisiä esityksiä julkaistaan edelleen kansainvälisesti (ks. esim. Švelch 2018). Saarikoski oli aiemmin tehnyt aihepiiristä suppeampia opinnäytetöitä (esim. Saarikoski 1999d; 2001).

Myös muut turkulaiset tutkijat vähintään sivusivat pelejä muussa tutkimuksessaan. Osana tietotekniikan varhaisvaiheita ja ensimmäisiä kansallisia tietokoneprojekteja käsitellyttä väitöstutkimustaan Petri Paju (2003) julkaisi artikkelin suomalaisesta NIM-pelin konstruktiosta. ${ }^{3}$ Paju suhteutti NIM-konstruktion erityisesti tietokoneiden kansalliseen kehitystyöhön mutta myös vastaaviin kokeiluihin muualla maailmassa.

Muista varhaisista digipelihistoriaan liittyvistä suomalaisten tutkijoiden artikkeleista mainittakoon Aki Järvisen Mariosofia-kirjassa julkaistu artikkeli pelien audiovisuaalisten tyylien kehityksestä (Järvinen 2003) sekä Pelit, tietokone ja ihminen -kirjassa jo vuonna 1999 julkaistu Petri Kuittisen englanninkielinen artikkeli Rogue-tyyppisten pelien ${ }^{4}$ sukupuusta (Kuittinen 1999).

\footnotetext{
${ }^{3}$ Nim-pelissä on kaksi tai useampi pelaajaa ja pelivälineinä on tietty määrä esimerkiksi tikkuja riveihin aseteltuina. Kukin pelaaja poistaa vuorollaan haluamansa määrän tikkuja yhdeltä riviltä. Häviäjä on se, jolle jää viimeinen tikku. (Paju 2003.) Nimin lisäksi varhaisilla keskustietokoneilla tehtiin kokeiluja esimerkiksi ristinollan ja shakin toteuttamiseksi.

4 Rogue-tyyppisissä peleissä seikkaillaan aarteita etsien tyypillisesti luolalabyrintissä, jossa vaanivat erilaiset hirviöt ja muut vaarat. Useimmiten näissä peleissä seikkailtava luolasto on toteutettu erittäin yksinkertaisella merkkigrafiikalla, ja pelejä on pelattu keskustietokoneympäristöissä. Tunnetuimpia lajityypin pelejä ovat Rogue, Hack ja Angband.
} 


\section{Tutkimuksen uudempia suuntauksia}

Vuonna 2009 ensimmäisen kerran ilmestynyt suomenkielinen Pelitutkimuksen vuosikirja on foorumi, jossa on säännöllisesti ilmestynyt pelihistorian artikkeleita sekä suppeampia katsauksia. Pelitutkimuksen vuosikirjan julkaisemista voikin pitää yhtenä käännekohtana myös suomenkielisen ja suomalaisen digipelihistorian tutkimuksessa. Yhteensä historiateemaan liittyviä artikkeleita ja katsauksia on vuosikirjoissa ilmestynyt yli kaksikymmentä. Varttuneempien tutkijoiden lisäksi lehdessä ovat julkaisseet myös väitöskirjantekijät ja maisteriopiskelijat. Yksittäiset artikkelit ja katsaukset ovat käsitelleet muun muassa 1980-luvun pelipiratismia (Nikinmaa 2012), antiikin Rooman lautapelejä (Tikka 2012), 1990-luvun pelilehtien lukijakirjeitä (Saarikoski 2012), ensimmäisiä suomalaisia pelejä ja peliyhtiöitä (Reunanen ym. 2013; Reunanen \& Pärssinen 2014), konsolipelien ensimmäistä buumia Suomessa 1980- ja 1990-luvun taitteessa (Suominen 2015), interaktiivisen tv-viihteen historiaa (Tuomi 2009), television mobiilipelejä (Kemppainen 2012), peleihin liittyneitä kohuja ja julkisen keskustelun historiaa (Pasanen 2011; 2014), Go-pelin pelaamisen vaiheita Suomessa (Luoma 2017), internetin Minigolf-pelin pelaajayhteisöä (Hämäläinen 2017) sekä pelaamisen elinkaarta muistitietoaineiston perusteella (Nevala 2017). Tyypillisesti tutkijat ovat käsitelleet pelejä ja pelaamista Suomessa, vaikka joitain poikkeuksiakin on ollut.

Monissa suomalaisissa pelejä koskevissa väitöskirjoissa ja pelitutkimuksen yleisesityksissä (ks. esim. Mäyrä 2008) on ollut myös jonkinlaisia historiaosuuksia, mutta en käsittele niitä tässä. Yksi laaja-alaisimmista pelihistoriaa käsitelleistä suomalaistutkijoista on Markku Reunanen, joka on tehnyt väitöskirjansa demoskenestä (2017). ${ }^{5}$ Reunanen on julkaissut kollegoineen suomeksi ja englanniksi useita artikkeleita, jotka käsittelevät demoskenen lisäksi muun muassa 1980-luvun eroottisiin peleihin liittyviä suomalaisia muistoja, Suomen ensimmäisiä kaupallisia pelijulkaisuja sekä yksittäisiä pelilajityyppejä, kuten länkkäripelejä ja itämaisia taistelulajipelejä kansainvälisestä näkökulmasta ja suhteessa saman aihepiirin elokuvatuotantoon. Näitä artikkeleita on julkaistu Pelitutkimuksen vuosikirjojen lisäksi WiderScreenissä ja useissa muissakin julkaisuissa. (Ks. Reunanen ym. 2011; Reunanen ym. 2013; Reunanen \& Pärssinen 2014; Heikkinen \& Reunanen 2013; Heikkinen \& Reunanen 2015; Suominen ym. 2018.)

Pelitutkimuksen vuosikirjan ja WiderScreenin (ks. myös esim. Vaahensalo 2015) lisäksi digipelihistoriaan liittyviä suomalaisia artikkeleita on julkaistu historian verkkolehdessä Ennen ja Nyt. Sen "Pelit ja historia"-teemanumerossa (2017) on käsitelty lautapelaamisen historiaa (Yänen 2017; Sihvonen 2017), liikunnan ja leikillisyyden yhteyksiä (Friman ym. 2017) ja Let's play -pelivideoita muistitietohistoriallisina lähteinä (Kerttula 2017). Ennen ja Nyt on julkaissut myös artikkelin digipelaamisen katsomisen historiasta (Suominen \& Lahdelma 2018). Myös Lähikuva-lehti on julkaissut pelihistoriaan liittyviä artikkeleita (esim. Pasanen \& Suominen 2018).

Rahapelaamisen historiantutkimus on sekin lisääntynyt Suomessa. Rahapelaamista on tarkasteltu erityisesti suomalaisten rahapeliorganisaatioiden kontekstissa (esim. Matilainen 2017; Ahonen 2018). Yksittäisiä avauksia on tehty myös esimerkiksi rahaja uhkapelaamisen pidemmän aikavälin oikeushistoriaan (Korpiola \& Sallila 2012).

Viime vuosina suomeksi on julkaistu tutkimusta myös lautapeleistä ja lautapelaamisesta. Esimerkiksi Lilli Sihvonen on tutkinut suomalaisen lautapelaamisen historia-

\footnotetext{
${ }^{5}$ Demoskene (engl. demoscene) on tietokoneharrastajien alakulttuuri, jossa ohjelmoidaan tietokoneelle audiovisuaalisesti näyttäviä ja koneiden suorituskyvyn rajoja koettelevia niin kutsuttuja demoja, joiden tekemisessä harrastajat kilpailevat tietokoneharrastajien tapahtumissa.
} 
kulttuuria sekä pelien kestäviä ja muuttuvia ominaisuuksia Suomessa vuonna 1967 esitellyn Kimble-pelin kautta (Sihvonen 2017; Sihvonen \& Sivula 2016). Henna Ylänen on tutkimassa puolestaan lautapelaamisen varhaisempaa historiaa (Ylänen 2017).

Pelihistorian tutkimus on vakiintunut Suomessa erityisesti Turun yliopiston digitaalisen kulttuurin oppiaineeseen. Sen lisäksi Suomen pelimuseo yhdessä Tampereen yliopiston pelikoulutusohjelman kanssa ovat lisänneet pelihistoriallista tutkimusta Tampereella, mikä näkyy opinnäytetöinä ja muina julkaisuina. Erityisesti pelimuseon ja Tampereen yliopiston tutkija Niklas Nylund on kirjoittanut pelihistoriaan sekä museotoimintaan liittyviä akateemisia tutkimuksia, usein englanniksi (esim. Nylund 2016; 2018), mutta muutkin tamperelaiset tutkijat ovat olleet aktiivisia tuomalla esiin erityisesti pelihistorioihin liittyviä henkilökohtaisia ja arkisia kokemuksia sekä osallistumalla Suomen pelimuseon kehitystyöhön (esim. Kultima \& Peltokangas 2016; Kultima \& Stenros 2018) ja tutkimalla peliteollisuuden muodonmuutoksia (esim. Jørgensen, Sandqvist \& Sotamaa 2015).

Akateemista tutkimusta on tukenut hyvin myös harrastajien monimuotoinen pelihistoriointi. Harrastajat ovat kirjoittaneet akateemisten tutkijoiden kanssa myös yhteisjulkaisuja, mutta yleensä heidän historia-aktiviteettinsa ovat ilmestyneet populaarimpina artikkeleina tai esimerkiksi videoblogien muodossa. ${ }^{6}$ Näiden lisäksi yksittäisiä tutkimuksia on tehty muuallakin, mutta aihealueesta kiinnostuneet opiskelijat ovat jääneet usein vaille erikoistunutta ohjausta, koska pelejä ja pelitutkimusta tuntevia ohjaajia ei ole ollut omassa oppiaineessa tai laitoksella. Pro gradu -tasoisia opinnäytetöitä on tehty esimerkiksi pelaamisesta ja muistitiedosta (esim. Nevala 2015; Kamsula 2015). Jyväskylän yliopistossa puolestaan erityisesti Tero Pasanen (esim. 2011; 2014; 2017; Pasanen \& Suominen 2018) ja Tero Kerttula (esim. Kerttula 2017; 2019) ovat tehneet pelihistoriallista tutkimusta.

Yhteenvetona voi todeta, että suomalaiset tutkijat julkaisevat edelleen pelihistorian tutkimusta englannin lisäksi suomeksi, vaikka suomenkielinen julkaiseminen on vähentynyt. Toisaalta pelihistorian tutkimus on yleisellä tasolla lisääntynyt, ja suomenkielistäkin tutkimusta ilmestyy säännöllisesti, vaikka sen osuus on pienentynyt. Tällä hetkellä tutkimuksessa ei ole mitään yhtä selkeää pääsuuntausta, vaan tutkimusaiheet, menetelmät ja aineistot vaihtelevat. Tutkimus käsittelee sekä itse historiaa että tutkimusaineistojen tallentamista, pitkäaikaissäilytystä, muistelua ja laajemmin peleihin liittyvää historiakulttuuria. Voi myös väittää, että ajankohtainen viihdepelaamiseen ja esimerkiksi rahapelaamiseen liittyvä keskustelu tuottaa uusia virikkeitä pelihistorian tutkimukselle, koska Suomessa esimerkiksi Veikkauksen toimintaa koskeva keskustelu vaatii nykytilanteen käsittelyn lisäksi historiallista ymmärrystä siitä, miksi rahapelimonopoli toimii Suomessa niin kuin toimii.

\section{Kiitän Suomen Akatemian rahoittamaa Pelikulttuurien tutkimuksen huippuyksikkö -hanketta (312396).}

\footnotetext{
6 Ks. esim. pelikeräilijä ja pelimuseoaktiivi Mikko Heinosen "Pelataanpa"-artikkelit V2-verkkolehdessä (esim. https://www.v2.fi/artikkelit/pelit/2441/Pelataanpa-Famicomia-kirppikselta/) ja samannimiset YouTube-videot.
} 


\section{Lähteet}

Ahonen, Jukka (2019) Kolme kriisiä ja kansalliset rahapelit: Yhteiskunnallisten murroskausien vaikutus suomalaisen rahapelijärjestelmän muotoutumiseen. Väitöskirja. Helsinki: Helsingin yliopisto. Saatavilla: <http://urn.fi/URN:ISBN:978-951-51-4778-3> (linkki tarkistettu 5.11.2019).

Friman, Usva; Rantala, Maria \& Turtiainen, Riikka (2017) Zombie Run Pori 2015 post-urheilullisena fyysisenä kulttuurina - suomalaisten juoksutapahtumien pelillistyminen ja leikillistyminen. Ennen ja nyt 1/2017 (Pelit ja historia -teemanumero). Saatavilla: <http://www.ennenjanyt.net/2017/01/zombie-runpori-2015-post-urheilullisena-fyysisena-kulttuurina-suomalaisten-juoksutapahtumien-pelillistyminenja-leikillistyminen/> (linkki tarkistettu 5.11.2019).

Haddon, Leslie (1988) The Roots And Early History of the British Home Computer Market: Origins of the Masculine Micro. London: Management School Imperial College, University of London.

Haddon, Leslie (1992) Explaining ICT consumption: the case of the home computer. Teoksessa Roger Silverstone \& Eric Hirsch (toim.), Consuming Technologies - Media and Information in Domestic Spaces. London and New York: Routledge, 82-112.

Haddon, Leslie (2002) Elektronisten pelien oppivuodet. Teoksessa Erkki Huhtamo \& Sonja Kangas (toim.), Mariosofia - Elektronisten pelien kulttuuri. Helsinki: Gaudeamus, 47-69.

Heikkinen, Tero \& Reunanen, Markku (2013) Kungfumestarit kuvaputkella - kamppailuelokuvien ja -pelien suhde 1980-luvulla. WiderScreen 4/2013 (Elokuvalliset pelit - pelilliset elokuvat -teemanumero). Saatavilla: <http://widerscreen.fi/numerot/2013-4/kungfumestarit-kuvaputkella-kamppailuelokuvienja-pelien-suhde-1980-luvulla/> (linkki tarkistettu 5.11.2019).

Heikkinen, Tero \& Reunanen, Markku (2015) Once Upon a Time on the Screen - Wild West in Computer and Video Games. WiderScreen 1-2/2015 (Villin lännen uudet visiot - New Visions of the Wild West-teemanumero). Saatavilla: <http://widerscreen.fi/numerot/2015-1-2/upon-time-screen-wild-westcomputer-video-games/> (linkki tarkistettu 5.11.2019).

Honkela, Timo (toim.) (1999) Pelit, tietokone ja ihminen. Suomen tekoälyseuran julkaisuja, Symposiosarja nro 15. Helsinki: Suomen Tekoälyseura.

Huhtamo, Erkki (2002) Vastakoneen vaiheet. Elektronisen pelikulttuurin arkeologiaa. Teoksessa Erkki Huhtamo \& Sonja Kangas (toim.), Mariosofia - Elektronisten pelien kulttuuri. Helsinki: Gaudeamus, 21-46.

Huhtamo, Erkki (2005) Slots of fun, slots of trouble: An archaeology of arcade gaming. Teoksessa Joost Raessens \& Jeffrey Goldstein (toim.), Handbook of computer game studies. Cambridge, MA: MIT Press, 3-22.

Huhtamo, Erkki (2012) What's Victoria Got To Do With It? Toward an Archaeology of Domestic Video Gaming. Teoksessa Mark J. P. Wolf (toim.), Before the Crash: Early Video Game History. Detroit: Wayne State University Press, 30-52.

Hämäläinen, Lasse (2017) Aapelin Minigolf: Pelaajayhteisön ja sen kulttuurin vaiheita. Teoksessa Raine Koskimaa, Jonne Arjoranta, Usva Friman, Frans Mäyrä, Olli Sotamaa \& Jaakko Suominen (toim.), Pelitutkimuksen vuosikirja 2017. Tampere: Suomen Pelitutkimuksen Seura, 49-59. Saatavilla: <http:// www.pelitutkimus.fi/vuosikirja2017/aapelin-minigolf-pelaajayhteison-ja-sen-kulttuurin-vaiheita> (linkki tarkistettu 5.11.2019).

Järvinen, Aki (2002) Kolmiulotteisuuden aika. Audiovisuaalinen kulttuurimuoto vuosina 1992-2002. Teoksessa Erkki Huhtamo \& Sonja Kangas (toim.), Mariosofia. Elektronisten pelien kulttuuri. Helsinki: Gaudeamus, 70-91.

Jørgensen, Kristine; Sandqvist, Ulf \& Sotamaa, Olli (2015) From hobbyists to entrepreneurs: On the formation of the Nordic game industry. Convergence: The International Journal of Research into New Media Technologies. First Published December 2, 2015. Saatavilla: <https://doi.org/10.1177/1354856515617853> (linkki tarkistettu 5.11.2019).

Kamsula, Tommi Antero (2015) Videopelimusiikkiin liittyvät muistot. Vuosina 1984-1990 syntyneiden haastattelukerronnan analyysi. Etnomusikologian pro gradu -työ. Joensuu: Itä-Suomen yliopisto. Saatavilla: $<$ http://urn.fi/urn:nbn:fi:uef-20150490> (linkki tarkistettu 5.11.2019).

Kemppainen, Jaakko (2012) Pelisuunnittelun erikoistapaus: tekstiviestit ja televisio. Teoksessa Jaakko Suominen, Raine Koskimaa, Frans Mäyrä \& Riikka Turtiainen (toim.), Pelitutkimuksen vuosikirja 2012. Tampere: Tampereen yliopisto. Saatavilla: <http://www.pelitutkimus.fi/vuosikirja2012/ptvk2012-13. pdf $>$ (linkki tarkistettu 5.11.2019).

Kerttula, Tero (2017) Let's Play pelikokemuksellisen muistitiedon tuottajana. Ennen ja nyt 1/2017 (Pelit ja historia -teemanumero). Saatavilla: $<$ http://www.ennenjanyt.net/2017/01/lets-play-pelikokemuksellisenmuistitiedon-tuottajana/> (linkki tarkistettu 5.11.2019). 
Kerttula, Tero (2019) The foundations of Let's Play: Live action representation of video games in television and online 1975-2018. Teoksessa Jonna Koivisto \& Juho Hamari (toim.), GamiFIN 2019: Proceedings of the 3rd International GamiFIN Conference. CEUR-WS.org. Saatavilla: <http://ceur-ws.org/Vol-2359/> (linkki tarkistettu 5.11.2019).

Kirkpatrick, Graeme (2012) Constitutive Tensions of Gaming's Field: UK gaming magazines and the formation of gaming culture 1981-1995. Game Studies 12(1). Saatavilla: <http://gamestudies.org/1201/ articles/kirkpatrick> (linkki tarkistettu 5.11.2019).

Korpiola, Mia \& Sallila, Jussi (2012) Uhkapelin oikeushistoriallisilla lähteillä. Teoksessa Pauliina Raento (toim.), Rahapelaaminen Suomessa. Helsinki: Gaudeamus, 43-65.

Kuittinen, Petri (1999) Roguelike Games. Teoksessa Timo Honkela (toim.), Pelit, tietokone ja ihminen. Suomen tekoälyseuran julkaisuja, Symposio-sarja nro 15. Helsinki: Suomen Tekoälyseura, 187-203.

Kultima, Annakaisa \& Peltokangas, Jouni (2017) Mistetyt, rakastetut, paheksutut, unohdetut. Avauksia suomalaisen pelihistorian laajaan kirjoon. Tampere: Mediamuseo Rupriikki.

Kultima, Annakaisa \& Stenros, Jaakko (toim.) (2018) Minun pelihistoriani. Henkilökohtaisia tarinoita suomalaisten pelaamisesta ja leikkimisestä. TRIM Research Reports 25. Tampere: Tampereen yliopisto.

Kuorikoski, Juho (2014) Sinivalkoinen pelikirja - Suomen pelialan kronikka 1984-2014. Sl: Fobos.

Kuorikoski, Juho (2017) Commodore 64 - Tasavallan tietokone. Helsinki: Minerva.

Luoma, Pirkko (2017) Go-lautapeliä Suomessa jo lähes 40 vuotta. Teoksessa Raine Koskimaa, Jonne Arjoranta, Usva Friman, Frans Mäyrä, Olli Sotamaa \& Jaakko Suominen (toim.), Pelitutkimuksen vuosikirja 2017. Tampere: Suomen Pelitutkimuksen Seura, 60-66. Saatavilla: <http://www.pelitutkimus.fi/ vuosikirja2017/go-lautapelia-suomessa-jo-lahes-40-vuotta> (linkki tarkistettu 5.11.2019).

Matilainen, Riitta (2012) Muistitietoaineistot rahapelaamisen tutkimuksessa. Teoksessa Pauliina Raento (toim.), Rahapelaaminen Suomessa. Helsinki: Gaudeamus, 161-179.

Matilainen, Riitta (2017) Production and Consumption of Recreational Gambling in Twentieth-Century Finland. Väitöskirja. Helsinki: Helsingin yliopisto. Saatavilla: <http://urn.fi/URN:ISBN:978-951-51-3282-6> (linkki tarkistettu 5.11.2019).

Mäyrä, Frans (2008) An Introduction to Game Studies. Games in Culture. Los Angeles: SAGE Publications.

Nevala, Tuulia (2015) Pelaamisen elinkaari: 1978-1985 syntyneiden pelihistoriaa Etelä-Pohjanmaalta. Internet- ja pelitutkimuksen pro gradu -tutkielma. Tampere: Tampereen yliopisto. <http://urn.fi/ URN:NBN:fi:uta-201601111058> (linkki tarkistettu 5.11.2019).

Nevala, Tuulia (2017) Pelaamisen elinkaari - pelien merkitykset elämän eri vaiheissa. Teoksessa Raine Koskimaa, Jonne Arjoranta, Usva Friman, Frans Mäyrä, Olli Sotamaa \& Jaakko Suominen (toim.), Pelitutkimuksen vuosikirja 2017. Tampere: Suomen Pelitutkimuksen Seura, 4-17. Saatavilla: <http://www. pelitutkimus.fi/vuosikirja2017/pelaamisen-elinkaari-pelien-merkitykset-elaman-eri-vaiheissa> (linkki tarkistettu 5.11.2019).

Nikinmaa, Joona (2012) Kun ohjelmistopiratismi saapui Suomeen - Ohjelmistopiratismi kuluttajien keskuudessa vuosina 1983-1985. Teoksessa Jaakko Suominen, Raine Koskimaa, Frans Mäyrä \& Riikka Turtiainen (toim.) Pelitutkimuksen vuosikirja 2012. Tampere: Tampereen yliopisto, 11-20. <http://www. pelitutkimus.fi/vuosikirja2012/ptvk2012-03.pdf> (linkki tarkistettu 5.11.2019).

Nylund, Niklas (2016) The early days of Finnish game culture: Game-related discourse in Micropost and Floppy Magazine in the mid-1980s. Cogent Arts \& Humanities 3(1). Saatavilla: <https://doi.org/10. 1080/23311983.2016.1191124> (linkki tarkistettu 5.11.2019).

Nylund, Niklas (2018) Constructing Digital Game Exhibitions: Objects, Experiences, and Context. Arts 2018, 7(4) (Special Issue Born Digital Cultural Histories). Saatavilla: <https://doi.org/10.3390/arts7040103> (linkki tarkistettu 5.11.2019).

Paju, Petri (2003) Huvia hyödyn avuksi jo 1950-luvulla - Nim-pelin rakentaminen ja käyttö Suomessa. WiderScreen 2-3/2003. Saatavilla: <http://widerscreen.fi/2003-2-3/huvia-hyodyn-avuksi-jo-1950-luvulla/> (linkki tarkistettu 5.11.2019).

Paju, Petri (2008) "Ilmarisen Suomi" ja sen tekijät. Matematiikkakonekomitea ja tietokoneen rakentaminen kansallisena kysymyksenä 1950-luvulla. Kulttuurihistorian väitöskirja. Turku: Turun yliopisto. Saatavilla: <http://urn.fi/URN:ISBN:978-951-29-3565-9> (linkki tarkistettu 5.11.2019).

Pantzar, Mika (1996) Kuinka teknologia kesytetään. Helsinki: Hanki ja Jää.

Parikka, Jussi \& Suominen, Jaakko (2006) Victorian Snakes? Towards a Cultural History of Mobile Games and the Experience of Movement. Game Studies 6(1). Saatavilla: <http://gamestudies.org/0601/ articles/parikka_suominen> (linkki tarkistettu 5.11.2019). 
Pasanen, Tero \& Suominen, Jaakko (2018) Epäonnistunut yritys suomalaisen digitaalisen peliteollisuuden käynnistämiseksi: Amersoft 1984-1986. Lähikuva 31(4). Saatavilla: <https://doi.org/10.23994/ lk.77932> (linkki tarkistettu 5.11.2019).

Pasanen, Tero (2011) 'Hyökkäys Moskovaan!' - Tapaus Raid over Moscow Suomen ja Neuvostoliiton välisessä ulkopolitiikassa 1980-luvulla. Teoksessa Jaakko Suominen, Raine Koskimaa, Frans Mäyrä, Olli Sotamaa \& Riikka Turtiainen (toim.), Pelitutkimuksen vuosikirja 2011. Tampere: Tampereen yliopisto, 1-11. Saatavilla: <http://www.pelitutkimus.fi/vuosikirja2011/ptvk2011-01.pdf> (linkki tarkistettu 5.11.2019).

Pasanen, Tero (2014) Murhasimulaattoreista poliittiseen korrektiuteen: Väkivalta pelikohujen arkkityyppinä. Teoksessa Jaakko Suominen, Raine Koskimaa, Petri Saarikoski \& Olli Sotamaa (toim.), Pelitutkimuksen vuosikirja 2014. Tampere: Tampereen yliopisto, 8-23. Saatavilla: <http://www.pelitutkimus. fi/vuosikirja2014/ptvk2014-02.pdf> (linkki tarkistettu 5.11.2019).

Pasanen, Tero (2017) Beyond the pale: gaming controversies and moral panics as rites of passage. Doctoral dissertation of Digital Culture. Jyväskylä: University of Jyväskylä. Saatavilla: <http://urn.fi/ URN:ISBN:978-951-39-7152-6> (linkki tarkistettu 5.11.2019).

Reunanen, Markku; Lankoski, Petri \& Heinonen, Mikko (2011) Joystickit kuumina - varhaista erotiikkaa kotitietokoneilla. Teoksessa Petri Saarikoski; Ulla Heinonen \& Riikka Turtiainen (toim.), Digirakkaus 2.0. Kulttuurituotannon ja maisemantutkimuksen julkaisuja 31. Pori: Turun yliopisto, 33-60. Saatavilla: <http://www.kameli.net/ marq/joystickit_kuumina.pdf> (linkki tarkistettu 5.11.2019).

Reunanen, Markku \& Pärssinen, Manu (2014) Chesmac: ensimmäinen suomalainen kaupallinen tietokonepeli - jälleen. Teoksessa Jaakko Suominen, Raine Koskimaa, Petri Saarikoski \& Olli Sotamaa (toim.), Pelitutkimuksen vuosikirja 2014. Tampere: Tampereen yliopisto, 76-80. Saatavilla: <http://www. pelitutkimus.fi/vuosikirja2014/ptvk2014-07.pdf> (linkki tarkistettu 5.11.2019).

Reunanen, Markku (2017) Times of Change in the Demoscene: A Creative Community and Its Relationship with Technology. Doctoral Dissertation of Digital Culture. Pori: University of Turku. Saatavilla: <http:// urn.fi/URN:ISBN:978-951-29-6717-9> (linkki tarkistettu 5.11.2019).

Saarikoski, Petri; Suominen, Jaakko \& Reunanen, Markku (2017) Pac-Man for the VIC-20: Game Clones and Program Listings in the Emerging Finnish Home Computer Market. Well Played 6(2), 7-31. Saatavilla: <http://repository.cmu.edu/cgi/viewcontent.cgi?article=1042\&context=etcpress> (linkki tarkistettu 5.11.2019).

Saarikoski, Petri \& Suominen, Jaakko (2009) Computer Hobbyists and the Gaming Industry in Finland. IEEE Annals of the History of Computing 31(3), 20-33.

Saarikoski, Petri \& Suominen, Jaakko (2009) Pelinautintoja, ohjelmointiharrastusta ja liiketoimintaa. Tietokoneharrastuksen ja peliteollisuuden suhde Suomessa toisen maailmansodan jälkeen. Teoksessa Jaakko Suominen, Raine Koskimaa, Frans Mäyrä \& Olli Sotamaa (toim.), Pelitutkimuksen vuosikirja 2009. Tampere: Tampereen yliopisto. Saatavilla: <http://www.pelitutkimus.fi/wp-content/uploads/2009/08/ ptvk2009-02.pdf> (linkki tarkistettu 5.11.2019).

Saarikoski, Petri (1998) Elokuva ja tietokonepelit. Vaeltava katse 1990-luvulla. WiderScreen 2/1998. Saatavilla: <http://widerscreen.fi/1998/2/elokuva_ja_tietokonepelit.htm> (linkki tarkistettu 5.11.2019).

Saarikoski, Petri (1999a) Suomalainen tietokonepelikulttuuri ja populaari mikrolehdistö 1980-luvulla osana nuorten poikien kotimikroharrastusta. Teoksessa Timo Honkela (toim.), Pelit, tietokone ja ihminen. Suomen tekoälyseuran julkaisuja, Symposiosarja, n:o 15. Helsinki: Suomen tekoälyseura.

Saarikoski, Petri (1999b) Tietokone- ja videopelit uuden median murroksessa 1990-luvulla. Teoksessa Petri Saarikoski, Hannu Nieminen, Jaakko Suominen (toim.), Uusi media ja arkielämä. Kirjoituksia uuden ajan kulttuurista. Viestintä, Turun yliopisto, Julkaisuja nr. 41 (Sarja A). Turku: Turun yliopisto.

Saarikoski, Petri (1999c) Tietokonepelit osana audiovisuaalisen kulttuurin moraalipaniikkia. WiderScreen 1-2/1999. Saatavilla: <http://www.widerscreen.fi/1999-1-2/tietokonepelit-osana-audiovisuaalisenkulttuurin-moraalipaniikkia> (linkki tarkistettu 5.11.2019).

Saarikoski, Petri (1999d) Populaari tietokonelehdistö kotimikrokulttuurin määrittäjänä Suomessa 1980-luvulla. Kulttuurihistorian julkaisematon laudatur-työ. Turku: Turun yliopisto.

Saarikoski, Petri (2001) Pioneerien leluista kulutuselektroniikaksi. Suomalainen kotimikroharrastus tietotekniikan murroksessa 1980-luvun alusta 1990-luvun puoliväliin. Yleisen historian julkaisematon lisensiaatintutkielma. Turku: Turun yliopisto.

Saarikoski, Petri (2003) Tietokonepelit ennen ja nyt. Kotimikrolehdistö ja tietokonepelikulttuurin alkuvaiheet Suomessa. Teoksessa Tanja Sihvonen, Pasi Väliaho (toim.), Mediaa kokemassa: koosteita ja ylityksiä. Experiencing the Media. Assemblages and Cross-overs. Turun yliopisto, Taiteiden tutkimuksen laitos, Mediatutkimus, Sarja A, nr 53. Turku: Turun yliopisto.

Saarikoski, Petri (2004) Koneen lumo. Mikrotietokoneharrastus Suomessa 1970-luvulta 1990-luvun puoliväliin. Nykykulttuurin tutkimuskeskuksen julkaisuja 83. Jyväskylä: Jyväskylän yliopisto. Saatavilla: <https:// jyx.jyu.fi/handle/123456789/55764> (linkki tarkistettu 5.11.2019). 
Saarikoski, Petri (2012) 'Rakas Pelit-lehden toimitus...' Pelit-lehden lukijakirjeet ja digipelaamisen muutos Suomessa vuosina 1992-2002. Teoksessa Jaakko Suominen, Raine Koskimaa, Frans Mäyrä \& Riikka Turtiainen (toim.), Pelitutkimuksen vuosikirja 2012. Tampere: Tampereen yliopisto, 21-40. Saatavilla: <http://www.pelitutkimus.fi/vuosikirja2012/ptvk2012-04.pdf> (linkki tarkistettu 5.11.2019).

Salmi, Hannu (1996) "Atoomipommilla kuuhun!" Tekniikan mentaalihistoriaa. Helsinki: Edita.

Sihvonen, Lilli \& Sivula, Anna (2016) Klassikoksi rakennettu - erään lautapelin historia. Teoksessa Raine Koskimaa, Jonne Arjoranta, Usva Friman, Frans Mäyrä, Olli Sotamaa, Jaakko Suominen (toim.), Pelitutkimuksen vuosikirja 2016. Tampere: Suomen Pelitutkimuksen Seura, 38-51. Saatavilla: <http:// www.pelitutkimus.fi/vuosikirja2016/klassikoksi-rakennettu-eraan-lautapelin-historia> (linkki tarkistettu 5.11.2019).

Sihvonen, Lilli (2017) Kestävyys ja Pop-O-Matic-muovikupu. Kimble-lautapelin pysyvien ominaisuuksien merkitys. Ennen ja Nyt 1/2017 (Pelit ja historia -teemanumero). Saatavilla: <http://www.ennenjanyt.net/2017/01/pop-o-matic-muovikupu-ja-kestavyys-kimbe-lautapelin-pysyvien-ominaisuuksienmerkitys/> (linkki tarkistettu 5.11.2019).

Sotamaa, Olli (2009) Suomalaisen pelitutkimuksen monet alut. Teoksessa Jaakko Suominen, Raine Koskimaa, Frans Mäyrä, Olli Sotamaa (toim.), Pelitutkimuksen vuosikirja 2009. Tampere: Tampereen yliopisto, 100-105. Saatavilla: <http://www.pelitutkimus.fi/wp-content/uploads/2009/08/ptvk2009-09. pdf $>$ (linkki tarkistettu 5.11.2019).

Stuckey, Helen; Swalwell, Melanie; Ndalianis, Angela \& de Vries, Denise (2015) Remembering \& Exhibiting Games Past: The Popular Memory Archive. Transactions of the Digital Games Research Association (ToDiGRA), Vol 2, No 1. Saatavilla: <http://todigra.org/index.php/todigra/article/view/40/79> (linkki tarkistettu 5.11.2019).

Suominen, Jaakko \& Lahdelma, Päivi (2018) Tuijotusta, tarkkailua ja osallistumista - Digitaalisen pelaamisen ja tietokoneiden käytön katsominen kuvissa 1980-luvulta 1990-luvulle. Ennen ja nyt 4/2018 (Kuva historiantutkimuksessa -teemanumero, toim. Olli Kleemola). Saatavilla: <http://www.ennenjanyt. net/2018/12/tuijotusta-tarkkailua-ja-osallistumista-digitaalisen-pelaamisen-ja-tietokoneiden-kaytonkatsominen-kuvissa-1980-luvulta-1990-luvulle/> (linkki tarkistettu 5.11.2019).

Suominen, Jaakko \& Parikka, Jussi (2010) Sublimated Attractions - The Introduction of Early Computers in Finland in the late 1950s as a Mediated Experience. Media History 16:3 (August 2010), 319-340.

Suominen, Jaakko; Reunanen, Markku \& Remes, Sami (2015) Return in Play: The Emergence of Retrogaming in Finnish Computer Hobbyist and Game Magazines from the 1980s to the 2000s. Kinephanos - Canadian Journal of Media Studies, Special Issue, June 2015, Edited by Jonathan Lessard, Martin Picard \& Carl Therrien. Saatavilla: <http://www.kinephanos.ca/2015/emergence-of-retrogaming/> (linkki tarkistettu 5.11.2019).

Suominen, Jaakko; Saarikoski, Petri \& Reunanen, Markku (2018) Digitaalisen kilpapelaamisen esihistoriaa Suomessa 1980-luvulta 1990-luvun puoliväliin. Teoksessa Raine Koskimaa, Jonne Arjoranta, Usva Friman, Frans Mäyrä, Olli Sotamaa, Jaakko Suominen (toim.), Pelitutkimuksen vuosikirja 2018. Tampere: Suomen Pelitutkimuksen Seura, 5-34. Saatavilla: <http://www.pelitutkimus.fi/vuosikirja2018/ digitaalisen-kilpapelaamisen-esihistoriaa-suomessa-1980-luvulta-1990-luvun-puolivaliin> (linkki tarkistettu 5.11.2019).

Suominen, Jaakko; Sivula, Anna \& Garda, Maria B. (2018) Incorporating Curator, Collector and Player Credibilities: Crowdfunding Campaign for the Finnish Museum of Games and the Creation of Game Heritage Community. Kinephanos - Canadian Journal of Media Studies, Special Issue Preserving Play, edited by Alison Gazzard \& Carl Therrien, August 2018. Saatavilla: <https://www.kinephanos.ca/2018/ incorporating-curator-collector-and-player-credibilities-crowdfunding-campaign-for-the-finnishmuseum-of-games-and-the-creation-of-game-heritage-community/> (linkki tarkistettu 5.11.2019).

Suominen, Jaakko \& Sivula, Anna (2016) Participatory Historians in Digital Cultural Heritage Process - Monumentalization of the First Finnish Commercial Computer Game. Refractory - Australian Journal of Entertainment Media, volume 27, 2016 - Themed issue: Born Digital Cultural Heritage. Saatavilla: $<$ http://refractory.unimelb.edu.au/2016/09/02/suominen-sivula/> (linkki tarkistettu 5.11.2019).

Suominen, Jaakko (1999) Elektronisen pelaamisen historiaa lajityyppien kautta tarkasteltuna. Teoksessa Timo Honkela (toim.), Pelit, tietokone ja ihminen. Suomen tekoälyseuran julkaisuja, Symposio-sarja nro 15. Helsinki: Suomen Tekoälyseura, 70-86.

Suominen, Jaakko (2001) Salora Playmaster - peliä televisiolla. Lisäarvon tuottaminen teknisten innovaatioiden yhteyteen. Teoksessa Tanja Sihvonen (toim.), Sähköä, säpinää, wapinaa. Risteilyjä teknologian kulttuurihistoriassa. Turun yliopiston historian laitoksen julkaisuja 59. Turku: Turun yliopisto, 97-104.

Suominen, Jaakko (2003) Koneen kokemus. Tietoteknistyvä kulttuuri modernisoituvassa Suomessa 1920-luvulta 1970-luvulle. Tampere: Vastapaino. Saatavilla: <https://jaasuo.files.wordpress.com/2017/05/koneen_kokemus_pieni.pdf $>$ (linkki tarkistettu 5.11.2019). 
Suominen, Jaakko (2008) The Past as the Future? Nostalgia and Retrogaming in Digital Culture. Fibreculture, issue 11. Saatavilla: <http://journal.fibreculture.org/issue11/issue11_suominen.html> (linkki tarkistettu 5.11.2019).

Suominen, Jaakko (2010) 'Pieni askel ihmiskunnalle, mutta jättiharppaus tietokoneistetuille roolipeleille' MikroBitti-lehden peliarvostelut pelaamisen historiatietoisuuden rakentajina 1984-2008. Teoksessa Jaakko Suominen, Raine Koskimaa, Frans Mäyrä \& Olli Sotamaa (toim.), Pelitutkimuksen vuosikirja 2010. Tampere: Tampereen yliopisto, 83-98. Saatavilla: <http://www.pelitutkimus.fi/vuosikirja2010/ ptvk2010-08.pdf> (linkki tarkistettu 5.11.2019).

Suominen, Jaakko (2011) Game Reviews as Tools in the Construction of Game Historical Awareness in Finland, 1984-2010: Case MikroBitti Magazine. Think, Design, Play - Digra2011 conference. Utrecht School of the Arts, Hilversum 14-17, September 2011. Saatavilla: <http://www.digra.org/dl/db/11310.15375. pdf> (linkki tarkistettu 5.11.2019).

Suominen, Jaakko (2012) Mario's legacy and Sonic's heritage: Replays and refunds of console gaming history. Proceedings of DiGRA Nordic 2012. Edited by Raine Koskimaa, Frans Mäyrä, Jaakko Suominen. Tampere, University of Tampere. Saatavilla: <http://www.digra.org/dl/display_html?chid=http://www. digra.org/dl/db/12168.57359.pdf> (linkki tarkistettu 5.11.2019).

Suominen, Jaakko (2015) Suomen ensimmäinen konsolipelibuumi 1988-1994 tietokonelehdistön ja pelaajien muistitiedon kautta tarkasteltuna. Teoksessa Raine Koskimaa, Jaakko Suominen, Frans Mäyrä, J. Tuomas Harviainen, Usva Friman \&, Jonne Arjoranta (toim.), Pelitutkimuksen vuosikirja 2015. Tampere: Tampereen yliopisto. Saatavilla: <http://www.pelitutkimus.fi/vuosikirja2015/artikkeli-suomen-ensimmainen-konsolipelibuumi-1988-1994-tietokonelehdiston-ja-pelaajien-muistitiedon-kauttatarkasteltuna> (linkki tarkistettu 5.11.2019).

Suominen, Jaakko (2016) How to Present the History of Digital Games: Enthusiast, Emancipatory, Genealogical and Pathological Approaches. Games \& Culture. Saatavilla: <https://doi. org/10.1177/1555412016653341> (linkki tarkistettu 5.11.2019).

Swalwell Melanie (2005) Early Games Production in New Zealand. DiGRA '05 - Proceedings of the 2005 DiGRA International Conference: Changing Views: Worlds in Play. Saatavilla: <http://www.digra.org/ digital-library/publications/early-games-production-in-new-zealand/> (linkki tarkistettu 5.11.2019).

Swalwell Melanie (2015) CFP Game History and the Local. Kirjoittajakutsu. Saatavilla: <https://www. academia.edu/12430151/CFP_Game_History_and_the_Local> (linkki tarkistettu 5.11.2019).

Švelch, Jaroslav (2018) Gaming the Iron Curtain. How Teenagers and Amateurs in Communist Czechoslovakia Claimed the Medium of Computer Games. Cambridge, Massachusetts, London, England: MIT Press.

Tikka, Reko (2012) Antiikin Rooman lautapelit. Teoksessa Jaakko Suominen, Raine Koskimaa, Frans Mäyrä \& Riikka Turtiainen (toim.), Pelitutkimuksen vuosikirja 2012. Tampere: Tampereen yliopisto, 1-10. Saatavilla: <http://www.pelitutkimus.fi/vuosikirja2012/ptvk2012-02.pdf> (linkki tarkistettu 5.11.2019).

Tuomi, Pauliina (2009) Television interaktiivinen pelihetki. Television pelillisyys ja merkitys pelikokemusten tuottamisessa. Teoksessa Jaakko Suominen, Raine Koskimaa, Frans Mäyrä ja Olli Sotamaa (toim.), Pelitutkimuksen vuosikirja 2009. Tampere: Tampereen yliopisto, 34-48. Saatavilla: <http://www. pelitutkimus.fi/wp-content/uploads/2009/09/ptvk2009-03.pdf> (linkki tarkistettu 5.11.2019).

Vaahensalo, Elina (2015) Onko peleissä homoja? LGBT-hahmojen historia digitaalisissa peleissä. WiderScreen 3/2015 (Teemanumero: Eri- ja samanarvoisuus digitaalisessa maailmassa - Equality and inequality in digital environments). Saatavilla: <http://widerscreen.fi/numerot/2015-3/onko-peleissahomoja-lgbt-hahmojen-historia-digitaalisissa-peleissa> (linkki tarkistettu 5.11.2019).

Ylänen, Henna (2017) Kansakunta pelissä. Nationalismi ja konfliktit 1900-luvun alun suomalaisissa lautapeleissä. Ennen ja Nyt 1/2017 (Pelit ja historia -teemanumero). Saatavilla: <http://www.ennenjanyt. net/2017/01/kansakunta-pelissa-nationalismi-ja-konfliktit-1900-luvun-alun-suomalaisissa-lautapeleissa/> (linkki tarkistettu 5.11.2019). 